\title{
KARAKTERISTIK DAN PERSEPSI WISATAWAN TERHADAP DAYA TARIK WISATA PANTAI KATA DI KOTA PARIAMAN, SUMATERA BARAT
}

\author{
Lucky Setiawana, 1, Ida Ayu Suryasiha, 2 \\ 1lucky.stwn@gmail.com,2iasuryasih@yahoo.com
}

a Program Studi S1 Destinasi Pariwisata, Fakultas Pariwisata,Universitas Udayana, Jl. Dr. R. Goris, Denpasar, Bali 80232 Indonesia

\begin{abstract}
Kata Beach as a tourist attraction has the potential and uniqueness of the coastal tourist attraction in general. But with the potential and uniqueness of the tourist attraction that should Kata Beach can attract more tourists, because at this time the number of tourists visiting the tourist attraction Kata still little and visited only at certain times such as the feast of Eid al-Fitr and the day-to-day national holiday. Local people who trade or sell around Kata Beach tourist attraction has yet to obtain maximum profit. This is caused by the time they trade and sell uncertain because they only sell at the moment busy travelers, if not crowded tourists who visit them do not open a shop to sell. Obviously this becomes a problem for the manager of a tourist attraction Kata Beach. To overcome these problems the need for improvements made by the manager of a tourist attraction Kata, by way of knowing in advance how the characteristics of tourists visiting Kata Beach, as well as knowing how travelers perception of the condition of Kata Beach is a tourist attraction at this point. So from the data manager can analyze the intended target market and to facilitate the development of decision-making will be done.

Collecting data in this study through observation, interviews, questionnaires, and Documentation studies. The type of data being used is supported by quantitative data and qualitative data. While the data sources used in the form of primary data and secondary data. Analysis using descriptive statistics which describe or illustrate the data that has been collected from a population, which is obtained by Likert Scale Data measurement techniques.

Characteristics of tourists visiting the tourist attraction Kata very good variety of indicators of gender, age, education, occupation and region of origin. While the perception of tourists on Kata Beach scored poorly on 6 indicators of security, number of toilets, cleanliness of restrooms, parking lot security, parking attendants skills and number of security officers. So it is necessary to reform by the manager for the indicators that scored poorly perceived by the tourists who visit.
\end{abstract}

Keywords: Characteristics, Perception, Tourist, Tourist Attractions, Kata Beach.

\section{PENDAHULUAN}

Pariwisata merupakan salah satu sektor yang diandalkan pemerintah untuk memperoleh devisa selain dari penghasilan non migas. Peranan pariwisata dalam pembangunan nasional, disamping sebagai sumber perolehan devisa juga banyak memberikan sumbangan terhadap bidang-bidang lainnya. Diantaranya menciptakan dan memperluas lapangan pekerjaan, meningkatkan pendapatan masyarakat dan pemerintah, mendorong pelestarian lingkungan hidup dan budaya bangsa, serta memperkokoh persatuan dan kesatuan bangsa dan lain sebagainya (Karyono, 1997:89).

Pariaman merupakan salah satu dari 19 kota dan kabupaten di Provinsi Sumatera Barat Indonesia. Kota Pariaman diresmikan sebagai kota otonom dengan diberlakukannya UU No.12 Th. 2002 dan merupakan pemekaran dari Kabupaten Padang Pariaman.
Salah satu daya tarik wisata yang sangat menarik dikunjungi wisatawan di Kota Pariaman adalah Pantai Kata. Pantai Kata terletak di Desa Taluak tepatnya terletak di dekat pusat Kota Pariaman. Aksesibilitas ke pantai ini sangat baik karena didukung oleh jaringan jalan menuju Bandara Internasional Minangkabau dan transportasi kota, jarak dari pusat kota adalah sekitar $3 \mathrm{~km}$.

Berbeda dengan pantai di Kota Pariaman lainnya, Pantai Kata sampai sekarang ini masih alami dan belum begitu terjamah. Keasrian dan panoramanya mampu menarik minat wisatawan untuk merasakan suasana harmoninya alam pantai yang indah dan asri. Salah satu keunikan yang dimiliki Pantai kata dari daya tarik wisata pantai lainnya di Kota Pariaman adalah Pantai Kata dikelilingi dengan pepohonan cemara yang rindang yang memberikan kesan asri dan sejuk di pantai ini, 
Vol. 4 No. 1, 2016

walapun daya tarik wisata pantai biasanya memiliki suhu yang panas.

Namun dengan potensi-potensi dan keunikan yang dimiliki oleh daya tarik wisata Pantai Kata tersebut seharusnya bisa menarik minat wisatawan lebih banyak lagi, karena pada saat ini jumlah wisatawan yang berkunjung ke daya tarik wisata Pantai Kata masih sedikit dan hanya ramai dikunjungi pada saat-saat tertentu seperti hari raya idul fitri dan hari-hari libur nasional. Masyarakat lokal yang berdagang atau berjualan di sekitar daya tarik wisata Pantai Kata pun belum memperoleh keuntungan yang maksimal. Hal ini disebabkan oleh waktu mereka berdagang dan berjualan yang tidak menentu karena mereka hanya berjualan pada saat wisatawan ramai saja, jika wisatawan yang berkunjung tidak ramai mereka tidak membuka warung untuk berjualan.

Dengan adanya kegiatan kepariwisataan di Pantai Kata saat ini, dirasakan masyarakat lokal di sekitar Pantai Kata belum memberikan pendapatan yang maksimal bagi mereka. Tentu hal ini perlu mendapat perhatian dari pihak pengelola daya tarik wisata Pantai Kata agar permasalahan tersebut bisa diselesaikan. Untuk mengatasi permasalahan tersebut perlu adanya pembenahan yang dilakukan oleh pengelola daya tarik wisata Pantai Kata, dengan mengetahui terlebih dahulu bagaimana karakteristik wisatawan yang berkunjung ke Pantai Kata. Sehingga dari data tersebut pihak pengelola dapat menganalisa target pasar yang dituju dan dapat mempermudah dalam mengambil keputusan pengembangan yang akan dilakukan.

Faktor berikutnya yang juga penting bagi pengembangan suatu daya tarik wisata adalah kualitas daya tarik wisata itu sendiri. Karena kualitas suatu daya tarik wisata sejatinya tidak bisa dinilai dari pengamatan pengelola saja tetapi perlu adanya persepsi dari wisatawan juga. Karena wisatawan sendiri yang bisa menilai apakah suatu daya tarik wisata tersebut sudah memenuhi kebutuhan mereka, atau masih adanya aspek-aspek yang perlu diperbaiki. Persepsi wisatawan juga sangat dibutuhkan oleh pihak pengelola suatu daya tarik wisata sebagai bahan acuan untuk melakukan pembenahan.

\section{KAJIAN PUSTAKA}

\subsection{Konsep Wisatawan.}

Menurut (Soekadijo, 2000), wisatawan adalah pengunjung di Negara yang dikunjunginya setidak-tidaknya tinggal 24 jam dan yang datang berdasarkan motivasi:

1. Mengisi waktu senggang atau untuk bersenang-senang, berlibur, untuk alasan kesehatan, studi, keluarga, dan sebagainya.

2. Melakukan perjalanan untuk keperluan bisnis.

3. Melakukan perjalanan untuk mengunjungi pertemuan-pertemuan atau sebagai utusan (ilmiah, administrative, diplomatik, keagamaan, olahraga dan sebagainya).

4. Dalam rangka pelayaran pesiar, jika kalau ia tinggal kurang dari 24 jam.

\subsection{Konsep Karakteristik}

\section{a. Karakteristik Sosio-demografis}

Karakteristik sosio-demografis mencoba menjawab pertanyaan "who wants what". Pembagian berdasarkan karakteristik ini paling sering dilakukan untuk kepentingan analisis pariwisata, perencanaan dan pemasaran, karena sangat jelas definisinya dan relatif mudah pembagiannya (Kotler, 1996).Yang termasuk dalam karakteristik sosio-demografis diantaranya adalah jenis kelamin, umur, status perkawinan, tingkat pendidikan, pekerjaan, kelas sosial, ukuran keluarga atau jumlah anggota keluarga dan lain-lain yang dielaborasi dari karakteristik tersebut.

b. Karakteristik geografis

Karakteristik geografis membagi wisatawan berdasarkan lokasi tempat tinggalnya, biasanya dibedakan menjadi desa-kota, propinsi, maupun negara asalnya. Pembagian ini lebih lanjut dapat pula dikelompokkan berdasarkan ukuran (size) kota tempat tinggal (kota kecil, menengah, besar/metropolitan), kepadatan penduduk di kota tersebut dan lain-lain.

c. Karakteristik psikografis

Sementara itu karakteristik psikografis membagi wisatawan ke dalam kelompokkelompok berdasarkan kelas sosial, life-style dan karakteristik personal. Wisatawan dalam kelompok demografis yang sama mungkin memiliki profil psikografis yang sangat berbeda.

Beragamnya karakteristik dan latar belakang wisatawan menyebabkan beragamnya keinginan dan kebutuhan mereka akan suatu produk wisata. Pengelompokanpengelompokan wisatawan dapat memberi 
informasi mengenai alasan setiap kelompok mengunjungi objek wisata yang berbeda, berapa besar ukuran kelompok tersebut, pola pengeluaran setiap kelompok, "kesetiaannya" terhadap suatu produk wisata tertentu, sensitivitas mereka terhadap perubahan harga produk wisata, serta respon kelompok terhadap berbagai bentuk iklan produk wisata. Lebih lanjut, pengetahuan mengenai wisatawan sangat diperlukan dalam merencanakan produk wisata yang sesuai dengan keinginan kelompok pasar tertentu, termasuk merencanakan strategi pemasaran yang tepat bagi kelompok pasar tersebut.

\subsection{Konsep Persepsi}

Menurut Leavit (dalam Sobur, 2003:445) persepsi dalam arti sempit adalah penglihatan, bagaimana cara seseorang melihat sesuatu, sedangkan dalam arti luas persepsi adalah pandangan atau pengertian yaitu bagaimana seseorang memandang atau mengartikan sesuatu.

\section{METODE}

Jenis dan sumber data yang digunakan dalam penelitian ini adalah kualitatif dan kuantitatif, sumber data berupa data primer yaitu data yang diperoleh berupa hasil wawancara dan diskusi dengan masyarakat lokal dan observasi ke lapangan secara langsung. Data sekunder berupa data yang diperoleh dari literature-literatur yang berkaitan dengan penelitian ini seperti studi kepustakaan, dokumen-dokumen dari Dinas Pariwisata Kota Pariaman seperti jumlah kunjungan wisatawan ke kota pariaman, jumlah kunjungan wisatawan ke Pantai Kata, dan artikel-artikel lainnya yang berkaitan dengan penelitian ini. Teknik pengumpulan data pada penelitian ini mengunakan observasi, wawancara, kuesioner dan studi kepustakaan.

Teknik pengambilan sampel pada penelitian ini menggunakan quota sampling. Teknik quota sampling adalah teknik penentuan sampel berdasarkan pada jumlah yang ditentukan (Sugiono, 2006). Untuk mendapatkan berapa banyak populasi yang akan dicari serta berapa responden yang diberikan kuesioner, maka untuk mengetahui jumlahnya digunakan cara penghitungan Slovin (Slovin, dalam Riduwan, $2005: 65$ )

$$
\begin{aligned}
& \mathrm{n}=\mathrm{N} \\
& \mathrm{N}(\mathrm{d})^{2}+1
\end{aligned}
$$

$\mathrm{n}=$ sampel; $\mathrm{N}=$ populasi; $\mathrm{d}=$ nilai

presisi $95 \%$ atau sig, $=0,05$

misalnya, jumlah populasi adalah 125 , dan tingkat kesalahan yang dikehendaki adalah 5\%, maka jumlah sampel yang digunakan adalah:

$$
\mathrm{n}=\frac{\mathrm{N}}{\mathrm{N}(\mathrm{d})^{2}+1}=\frac{125}{125(0,05)^{2}+1}=95,23 \text { dibulatkan } 95 \text { sampel }
$$

Jadi cara mencari populasi wisatawan yang ada di Pantai Kata adalah dengan menggunakan slovin, dalam waktu satu hari (10.00 pagi s/d 23.00 malam) mendapatkan populasi sebanyak 97, kemudian dikelola dengan cara penghitungan slovin dan hasil yang didapatkan adalah 78,06 dibulatkan 78 wisatawan yang akan mendapatkan kuesioner.

Penelitian ini menggunakan teknik analisis statistik deskriptif yaitu mendeskripsikan atau menggambarkan data yang telah terkumpul dari suatu populasi (Sugiyono, 2010). Dengan metode analisis data statistik deskriptif tersebut diharapkan mampu mendeskripsikan dan menjelaskan bagaimana persepsi wisatawan terhadap daya tarik wisata Pantai Kata.

Untuk memperoleh dan mengukur data persepsi wisatawan terhadap Pantai Kata, maka penelitian ini menggunakan skala pengukuran Likert. Skala Likert adalah skala yang digunakan untuk mengukur sikap, pendapat, dan persepsi seseorang atau sekelompok orang tentang fenomena sosial (Sugiyono, 2010). Dengan skala likert, maka variabel yang akan diukur dijabarkan menjadi indikator variabel. Kemudian indikator tersebut dijadikan sebagai titik tolak untuk menyusun item-item instrumen yang dapat berupa pernyataan atau pertanyaan.

\section{HASIL DAN PEMBAHASAN \\ 4.1 Gambaran Umum Pantai Kata}

Pantai Kata terletak di selatan Kota Pariaman, pantai ini membentang diantara Desa Taluk dan Kelurahan Karan Aur. Jarak dari pusat Kota Pariaman ke Pantai Kata hanya $3 \mathrm{~km}$. Kata adalah nama dua desa yang berdekatan yaitu "Karan Aur dan Taluk". Karena berlokasi pada dua daerah ini, maka pantai indah ini dinamakan Pantai Kata. Pantai ini juga terkenal indah, dengan perpaduan kerindangan pepohonan cemara dan pasir putih yang indah. Menuju pantai ini, para wisatawan juga bisa menggunakan sarana trasportasi tradisional, yaitu bendi, ojek, dan angkutan kota. 
Vol. 4 No. 1, 2016

\subsection{Potensi Pantai Kata}

a. Bentuk Pantai Landai

Dengan bentuk pantai yang landai Pantai Kata sangat cocok digunakan sebagai tempat bermain air dan pasir bagi wisatawan keluarga. Ditambah lagi dengan pemandangan gugusan pulau-pulau kecil di depan Pantai Kata yang membuat wisatawan betah berlama-lama di pantai untuk menyaksikan pemandangan yang indah.

b. Pasir Putih

Pantai kata memiliki pasir putih yang bersih dan lembut, dengan pasir putih yang dimiliki oleh Pantai Kata dapat menambah keunikan tersendiri. Para wisatawan biasanya memilih pantai yang berpasir putih untuk dikunjungi. Karena dengan adanya pasir putih dapat memberikan kesan bersih dan eksotis bagi para wisatawan sehingga pantai dengan pasir putih sangat cocok untuk wisatawan keluarga yang bertujuan bermain pasir di pantai.

c. Udara yang segar

Pantai Kata memiliki udara yang segar karena letak pantai yang jauh dari jalan sehingga terbebeas dari asap polusi dari kendaraan bermotor. Ditambah dengan kehidupan masyarakat lokal yang menjaga keasrian pantai dan tidak merusak pantai dengan tidak membuang limbah kearah pantai, dapat memberikan suatu daya tarik tersendiri bagi Pantai Kata. Dengan adanya udara yang segar dapat memberikan ketenangan dan peluang bagi wisatawan yang akan berkunjung untuk berlama-lama di Pantai Kata.

d. Terdapat pepohonan cemara

Keunikan yang dimiliki Pantai Kata selanjutnya adalah terdapat pepohonan cemara yang berbaris rapi dan rindang di sepanjang Pantai Kata. pepohonan cemara di Pantai Kata membuat Pantai Kata menjadi semakin eksotis dan sangat nyaman dikunjungi. Karena membuat udara di pinggir pantai menjadi sejuk dan asri, sangat berbeda dengan pantai-pantai pada umumnya yang banyak dihiasi pepohonan kelapa. Jelas faktor ini sangat mempengaruhi minat kunjungan wisatawan untuk berkunjung ke suatu daya tarik wisata.

\subsection{Karakteristik Wisatawan \\ 4.2.1 Jenis Kelamin}

Berdasarkan dari hasil penelitian yang dilakukan di daya tarik wisata Pantai Kata, dari 78 orang wisatawan yang dijadikan sebagai responden maka diperoleh data sebagai berikut, jenis kelamin laki-laki yang mengunjungi Pantai Kata sebanyak 45 orang (58\%) dan jenis kelamin perempuan sebanyak 33 orang (42\%).

\subsubsection{Tingkat Usia}

Berdasarkan hasil penelitian yang dilakukan di daya tarik wisata Pantai Kata, dari 78 orang wisatawan yang dijadikan sebagai responden, diperoleh data bahwa bila ditinjau dari tingkat usia wisatawan diperoleh hasil wisatawan dari tingkat usia dibawah 15 tahun sebanyak 12 orang (15\%), wisatawan dari tingkat usia 16-25 tahun sebanyak 26 orang (33\%), tingkat usia 26-35 tahun sebanyak 20 orang (26\%), tingkat usia 36-45 tahun sebanyak 15 orang (20\%), dan wisatawan yang berusia diatas 45 tahun sebanyak 5 orang (6\%).

\subsubsection{Status Perkawinan}

Berdasarkan hasil penelitian yang dilakukan di daya tarik wisata Pantai Kata , dari 78 orang wisatawan yang dijadikan sebagai responden, diperoleh data bahwa wisatawan yang mengunjungi daya tarik wisata Pantai Kata jika dilihat dari status perkawinannya adalah lajang sebanyak 43 orang (55\%), menikah sebanyak 20 orang (26\%), duda sebanyak 9 orang (11\%), janda sebanyak 6 orang (8\%).

\subsubsection{Daerah Asal}

Berdasarkan hasil penelitian yang dilakukan di daya tarik wisata Pantai Kata, dari 78 orang wisatawan yang dijadikan sebagai responden, diperoleh data bahwa wisatawan yang mengunjungi daya tarik wisata Pantai Kata berasal dari berbagai daerah, yaitu; Pariaman sebanyak 26 orang (33\%), Padang sebanyak 9 orang (11\%), Bukittinggi sebanyak 10 orang $(13 \%)$, Sicincin sebanyak 15 orang (20\%), Medan sebanyak 3 orang (4\%), Aceh sebanyak 4 orang (5\%), Lampung sebanyak 3 orang (4\%), Pekanbaru sebanyak 6 orang (7\%), Jakarta sebanyak 2 orang (3\%).

\subsubsection{Tingkat Pendidikan}

Berdasarkan hasil penelitian yang dilakukan di daya tarik wisata Pantai Kata, dari 78 orang wisatawan yang dijadikan sebagai responden, diperoleh data bahwa wisatwan yang mengunjungi daya tarik wisata Pantai Kata dari berbagai tingkat pendidikan. Adapun detailnya adalah sebagai berikut; jumlah wisatawan yang tidak sekolah sebanyak 5 orang (6\%), SD sebanyak 7 orang (9\%), SMP sebanyak 13 orang (17\%), SMA sebanyak 30 
orang (38\%), Diploma sebanyak 15 orang (20\%), Sarjana sebanyak 8 orang (10\%).

\subsubsection{Pekerjaan}

Berdasarkan hasil penelitian yang dilakukan di daya tarik wisata Pantai Kata, dari 78 orang wisatawan yang dijadikan sebagai responden, diperoleh data bahwa wisatawan yang mengunjungi daya tarik wisata Pantai Kata berasal dari berbagai kalangan profesi. Adapun detailnya adalah sebagai berikut; pelajar/mahasiswa sebanyak 50 orang (64\%), PNS sebanyak 5 orang (6\%), Pegawai swasta sebanyak 6 orang (8\%), Wiraswasta sebanyak 7 orang (9\%) orang, Ibu rumah tangga sebanyak 10 orang $(13 \%)$.

\subsection{Persepsi Wisatawan Terhadap Daya Tarik Wisata Pantai Kata \\ 4.3.1 Persepsi Terhadap Kondisi Daya Tarik Wisata Pantai Kata}

Dari hasil pengolahan data yang diperolehdari 78 wisatawan yang dijadikan responden di daya tarik wisata Pantai Kata dan dengan menggunakan cara penghitungan Skala Likert, data dari variabel kondisi daya tarik wisata Pantai Kata menunjukan bahwa; indikator keunikan memperoleh penilaian persepsi sangat baik dengan skor 353, selanjutnya indikator keindahan memperoleh penilaian persepsi yang baik dari para wisatawan dengan skor 347, dan indikator keasrian mendapat penilaian persepsi yang baik dengan skor 320. Berikutnya indikator kebersihan memperoleh persepsi yang baik dari wisatawan dengan skor 287 dan urutan terakhir yang memperoleh persepsi yang kurang baik dari wisatawan adal indikator keamanan dengahn jumlah skor 176 .

\subsubsection{Persepsi Terhadap Aksesibilitas Daya Tarik Wisata Pantai Kata}

Dari hasil pengolahan data yang diperolehdari 78 wisatawan yang dijadikan responden di daya tarik wisata Pantai Kata dan dengan menggunakan cara penghitungan Skala Likert, data dari variabel aksesibilitas daya tarik wisata Pantai Kata menunjukan bahwa; indikator keterjangkauan angkutan umum memperoleh penilaian persepsi sangat baik dengan skor 358, selanjutnya indikator petunjuk jalan memperoleh penilaian persepsi yang baik dari para wisatawan dengan skor 348, dan indikator kualitas jalan mendapat penilaian persepsi yang baik dengan skor 347 .

\subsubsection{Persepsi Terhadap Fasilitas Daya Tarik Wisata Pantai Kata \\ Dari hasil pengolahan data yang} diperolehdari 78 wisatawan yang dijadikan responden di daya tarik wisata Pantai Kata dan dengan menggunakan cara penghitungan Skala Likert, data dari variabel fasilitas daya tarik wisata Pantai Kata menunjukan bahwa; indikator jumlah tempat sampah memperoleh penilaian persepsi yang baik dengan skor 311.Selanjutnya indikator luas tempat parkir memperoleh penilaian persepsi yang cukup baik dari para wisatawan dengan skor 209, dan indikator keamanan tempat parkir mendapat penilaian persepsi yangkurang baik dengan skor 176.

Berikutnya indikator kebersihan toilet memperoleh persepsi yang kurang baik dari wisatawan dengan skor 161 dan indikator jumlah toilet mendapatkan persepsi kurang baik dari wisatawan dengan skor 155 . Lalu indikator jumlah petugas kemanan juga mendapatkan persepsi yang kurang baik dari wisatawan dengan jumlah skor 154 dan urutan terakhir yang memperoleh persepsi yang kurang baik dari wisatawan adalah indikator keterampilan juru parkir dengan jumlah skor 150.

\section{SIMPULAN DAN SARAN}

\subsection{Simpulan}

Sesuai dengan permasalahan yang telah dirumuskan pada Bab I dan berdasarkan hasil penelitian yang telah dipaparkan dalam Bab IV, maka dapat disampaikan simpulan sebagai berikut:

1. Karakteristik wisatawan yang berkunjung ke daya tarik wisata Pantai Kata sangat beragam. Bisa dilihat dari indikator-indikator berikut; jenis kelamin laki-laki sebanyak 45 orang (58\%) dan perempuan sebanyak 33 orang (42\%). Adapun dari tingkat usia wisatawan yang paling banyak mengunjungi daya tarik wisata Pantai Kata adalah tingkat usia 16-25 tahun. Jika dilihat dari status perkawinan, yang paling mendominasi yaitu yang berstatus lajang sebanyak 43 orang atau (55\%).Wisatawan yang mengunjungi daya tarik wisata Pantai Kata berasal dari berbagai kota di Pulau Sumatera maupun dari luar Pulau Sumatera. Dilihat dari daerah asal yang paling mendominasi adalah berasal dari Kota Pariaman yaitu sebanyak 26 orang atau 33\%. 
Vol. 4 No. 1, 2016

Berdasarkan data yang diperoleh jika dilihat dari status pendidikan wisatawan di Pantai Kata, yang paling mendominasi adalah yang berstatus pendidikan SMA yaitu sebanyak 30 orang atau 38\%. Wisatawan yang berkunjung ke Pantai Kata juga memiliki latar belakang pekerjaan yang beragam seperti, pelajar/mahasiswa, PNS, pegawai swasta, wiraswasta dan ibu rumah tangga. Namun yang paling mendominasi adalah yang berstatus pekerjaan pelajar/mahasiswa yaitu sebanyak 50 orang atau $64 \%$.

2. Persepsi wisatawan terhadap daya tarik wisata Pantai Kata memperoleh nilai yang kurang baik, seperti indikator-indikator berikut: indikator keamanan dengan jumlah skor 176, indikator keamanan tempat parkir dengan skor 176, indikator kebersihan toilet dengan skor 161, indikator jumlah toilet dengan skor 155, indikator jumlah petugas keamanan dengan jumlah skor 154, dan indikator keterampilan juru parkir dengan jumlah skor 150. Walaupun tidak semua indikator pada setiap variabel mendapatkan nilai yang kurang baik, tetapi wisatawan merasakan ada kekurangan yang harus dibenahi agar kebutuhan dari wisatawan tersebut terpenuhi.

\section{DAFTAR PUSTAKA}

A.Hari Karyono. 1997. Kepariwisataan. Jakarta: Grasindo. Anonim, Undang-Undang Republik Indonesia No 10 Tahun 2009 tentang Kepariwisataan.

Anonim, Undang-Undang Republik Indonesia No 12 Tahun 2002 tentang Pembentukan Kota Pariaman di Provinsi Sumatera Barat.

Kotler, Philip.1996. Marketing. Jili 1 (edisi bahasa Indonesia dari marketing essentials). Diterjemahkan oleh : herujati purwato. Jakarta : Erlangga.

Riduwan. 2005. Skala Pengukuran Variabel-Variabel Penelitian. Bandung: Alfabeta.

Sobur, Alex. 2003. Psikologi Umum. Bandung: Pustaka Setia.

Soekadijo,R.G., 2000, Anatomi Pariwisata, Jakarta: Gremedia Pustaka Utama.

Sugiyono. 2006.Metode Penelitian Pendidikan. Bandung: Alfabeta.

Sugiyono. 2010. Metode Penelitian Kuantitatif Kualitatif dan R\&D. Bandung: Alfabeta.

\subsection{Saran}

Berdasarkan hasil penelitian yang telah diuraikan sebelumnya, maka dapat dikemukakan beberapa saran sebagai berikut:

1. Hasil penelitian menunjukan bahwa wisatawan yang berkunjung ke daya tarik wisata Pantai Kata memiliki karakteristik yang beragam. Jadi pihak pengelola perlu mempelajari data tersebut sebagai bahan acuan untuk memperoleh keputusan dan menentukan arah pengembangan daya tarik wisata Pantai Kata. Karena mengingat wisatawan yang datang berasal dari berbagai usia, jenis kelamin, daerah asal, status perkawinan, pendidikan dan pekerjaan.

2. Diharapkan pengelola dapat membenahi dan memperbaiki fasilitas-fasilitas yang ada di daya tarik wisata Pantai Kata seperti; keamanan, jumlah toilet, kebersihan toilet, keamanan tempat parkir, keterampilan juru parkir dan jumlah petugas keamanan. Karena indikator-indikator tersebut mendapatkan nilai yang kurang baik. Serta menjaga berbagai fasilitas yang sudah ada lainnya, agar wisatawan yang berkunjung memperoleh kenyamanan sehingga tidak menutup kemungkinan wisatawan tersebut akan berkunjung kembali ke daya tarik wisata Patai Kata. 